\title{
COST-EFFECTIVENESS PELAKSANAAN PROGRAM PENINGKATAN PELAYANAN BLUD DI RSUD Dr. SOETOMO SURABAYA
}

\author{
Dian Gayatri* Supriyanto* \\ *Prodi Administrasi Rumah Sakit STIKES Yayasan RS Dr. Soetomo \\ diangayatri17@gmail.com \\ supriyantosoekandar@gmail.com
}

\begin{abstract}
ABSTRAK
Pada tahun 2015 RSUD Dr Soetomo mempunyai 8 program yang sumber dana yang diperoleh dari dana APBD dan APBN. Penggunaan dana tersebut belum dilakukan pengukuran kinerja terhadap program yang dilakukan di Rumah Sakit. Pengukuran kinerja dapat diukur menggunakan metode Cost-Effectiveness yaitu perbandingan antara costoutcome dengan biaya program. Pengukuran Cost-Effectiveness dilakukan terhadap pelaksanaan program peningkatan pelayanan Badan Layanan Umum Daerah di RSUD Dr. Soetomo tahun 2015. Rancang bangun penelitian ini adalah penelitian deskriptif dengan telaah dokumen yang dilakukan terhadap dokumen SAKIP tahun 2015. Penelitian ini mengkaji efektifitas outcome yang dihasilkan dengan input (dana) yang dianggarkan. Subyek penelitian dalam penelitian ini adalah Dokumen Sistem Akuntabilitas Kinerja Instalasi Pemerintah yaitu Rencana strategis RSUD Dr. Soetomo Tahun 2015, Dokumen Rencana Kinerja Tahunan Tahun 2015, Dokumen Perubahan Pelaksanaan Anggaran Tahun 2015, Laporan Akuntabilitas Kinerja Instansi Pemerintah Tahun 2015. Analisa data yang digunakan adalah secara deskriptif yaitu analisis yang didasarkan pada perhitungan untuk mengetahui tingkat rasio. Hasil dari identifikasi input diketahui bahwa dana yang digunakan yaitu 87\% dari total dana yang dianggarkan. Output pada penelitian ini adalah jumlah sub kegiatan yang dilakukan untuk mendukung kegiatan yang dilakukan oleh setiap Bidang/Bagian. Output dapat juga berupa jumlah dokumen yang dihasilkan dari kegiatan tersebut. Outcome yang akan dicapai pada tahun 2015 adalah 14 IKU direktur. Outcome ini dicapai dalam waktu satu tahun dan pengukurannya dalam jangka waktu yang lama. Hasil penelitian ini menunjukkan dari 14 IKU Direktur ada 1 IKU termasuk dalam kategori Efektif, 11 IKU yang termasuk dalam kategori cukup efektif, 1 IKU termasuk dalam kategori kurang efektif, dan 1 IKU termasuk dalam kategori tidak efektif. Pelaksanaan kegiatan yang mendukung outcome 14 IKU tersebut berasal dari program peningkatan pelayanan Badan Layanan Umum Daerah di RSUD Dr. Soetomo tahun 2015, maka dapat disimpulkan bahwa pengukuran CostEffectiveness pelaksanaan program peningkatan pelayanan Badan Layanan Umum Daerah di RSUD Dr. Soetomo tahun 2015 termasuk dalam kategori cukup efektif.
\end{abstract}

Kata Kunci: Input, Outcome, Cost effectiveness

\section{ABSTRACT}

2015 Hospital Dr Soetomo having 8 program whose source of funds obtained from local government funds and the state budget. The use of these funds have not been carried out against the performance measurement program conducted at the Hospital. Measurement of performance can be measured using the method of Cost-Effectiveness which is the ratio between the cost-outcome with program costs. Cost-Effectiveness measurements carried out on the implementation of service improvement programs Regional P ublic Service at Hospital Dr. Soetomo 2015.The research design was a descriptive study with document review done to 
document SAKIP 2015. This study examines the effectiveness of the outcomes generated by input (funding) is budgeted. Research subjects in this study is the Performance Accountability System Document Government Installation is a strategic plan Hospital Dr. Soetomo 2015, Document Annual Performance Plan 2015, Document Changes in the budget 2015, Government Agencies Performance Accountability Report Year 2015. Analysis of the data used is descriptive qualitative analysis based on the calculation for determine the level ratio. The results of the identification input is known that the funds are used is $87 \%$ of the total budgeted funds. Output in this study is the number of sub-activities undertaken to support the activities conducted by each Division / Section. Output can also be the number of documents resulting from these activities. Outcome to be achieved by 2015 is 14 KPI's director. This outcome is achieved within one year and measurement in the long term. The results showed 14 KPI's Director of No 1 Effective KPI's included in the category, 11 KPI's included in the category is quite effective, 1 KPI's included in the category of less effective, and 1 KPI's included in the category are not effective. Implementation of activities that support the outcome of the 14 KPI's derived from service improvement programs Regional Public Service at Hospital Dr. Soetomo 2015, it can be concluded that the measurement of CostEffectiveness implementation of service improvement programs Regional Public Service at Hospital Dr. Soetomo 2015 included in the category is quite effective.

Keywords: Input, Outcomes, Cost-effectivenes $\backslash$

\section{Latar Belakang}

Rumah Sakit Umum Daerah Dr. Soetomo yang selanjutnya disebut RSUD Dr. Soetomo adalah salah satu rumah sakit tipe A milik pemerintah yang dalam pengelolaan keuangan harus berdasarkan pengelolaan keuangan Badan Layanan Umum Daerah (BLUD). Pengelolaan keuangan BLUD diterapkan oleh setiap instansi pemerintah yang secara fungsional menyelenggarakan kegiatan yang bersifat operasional. Dengan ditetapkannya RSUD Dr. Soetomo sebagai PPK BLUD maka RSUD Dr. Soetomo mempunyai kewenangan dalam mengelola keuangannya sendiri. Dalam mengelola keuangan RSUD Dr. Soetomo mempunyai asas fleksibilitas yaitu pendapatan operasional dapat digunakan langsung sesuai rencana bisnis dan anggarannya tanpa terlebih dahulu disetorkan ke Rekening Kas Negara/Daerah (Pasal 14 PP 23/2005). Pengelolaan keuangan BLUD harus dapat dipertanggung-jawabkan dalam Laporan Akuntabilitas Kinerja Pemerintah (LAKIP).

Pada laporan akuntabilitas kinerja instansi pemerintah didalamnya menjelaskan tentang pengukuran kinerja terhadap pelaksanaan program dan evaluasi terhadap pelaksanaan program. Pengukuran kinerja terhadap pelaksanaan program digunakan sebagai langkah awal untuk evaluasi program. Hasil dari evaluasi seharusnya digunakan sebagai bahan pertimbangan pengambilan keputusan dan digunakan untuk perencanaan program selanjutnya.

Evaluasi program perlu dilaksananakan secara rutin dan periodik sejak awal perencanaan, saat pelaksanaan dan hasilnya, dimaksudkan agar mengetahui gambaran menyeluruh program yang dilaksanakan. Evaluasi terutama didasarkan atas pemikiran yang rasional dan data yang terukur, agar dalam pengambilan keputusan dalam upaya menyelesaikan persoalan atau upaya peningkatan pelayanan berdasarkan penilaian objektif yang dapat dipertanggung jawabkan. Hasil evaluasi harus selalu diumpan balikkan kedalam proses manajemen, untuk perencanaan selanjutnya.

RSUD Dr. Soetomo adalah salah satu rumah sakit BLUD yang mempunyai 8 Program pada tahun 2015 yaitu: 
1. Program Pelayanan Administrasi Perkantoran yang berasal dari dana APBD (Non Fungsional)

2. Program Peningkatan Sarana Dan Prasarana Aparatur yang berasal dari dana APBD (Non Fungsional)

3. Program Peningkatan Kapasitas Kelembagaan Pemerintah Daerah yang berasal dari dana APBD (Non Fungsional)

4. Program Penyusunan, Pengen- dalian Dan Evaluasi Dokumen Penyelenggaraan Pemerintahan yang berasal dari dana APBD (Non Fungsional)

5. Program Upaya Kesehatan Perorangan yang berasal dari dana APBD (Non Fungsional)

6. Program Peningkatan Sarana Dan Prasarana Pelayanan Badan Layanan Umum Daerah (BLUD) yang berasal dari dana APBD (Non Fungsional)

7. Program Peningkatan Pelayanan Badan Layanan Umum Daerah (BLUD) yang berasal dari dana APBD (Fungsional)

8. Program Pembinaan Upaya Kesehatan yang berasal dari dana APBN.

Program tersebut adalah sumber dana yang diperoleh RSUD Dr.Soetomo yang bersumber dari dana APBD dan APBN. Pelaksanaan program diatas ditetapkan dengan visi, misi, tujuan, dan sasaran rumah sakit. Selain itu juga harus mendukung Indikator Kinerja Utama (IKU) direktur rumah sakit. Pengelolaan dana untuk program tersebut harus efisien dan efektif hal ini beracuan terhadap Peraturan Menteri Keuangan no 61 tentang Pengelolaan Keuangan BLUD.

Program yang sudah berjalan diatas harus dapat dipertanggung- jawabkan dan harus dapat diukur. Dalam pelaksanaan pengukuran kinerja yang telah dilakukan RSUD Dr. Soetomo sudah berdasarkan dengan PERMENPAN No. 53 Tahun 2014. RSUD Dr. Soetomo sudah melakukan pengukuran kinerja untuk mengetahui apakah program tersebut berjalan dengan baik. Menurut wawancara yang dilakukan dengan Ka Sub Bagian
Perencanaan Program diperoleh informasi bahwa belum dilakukan pengukuran kinerja dengan menggunakan metode Cost-Effectiveness. Cost-Effectiveness adalah perbandingan antara cost-outcome dengan biaya program. Penelitian ini sangat penting untuk dilakukan karena Cost-Effectiveness ini bertujuan mengidentifikasi biaya yang digunakan untuk menghasilkan suatu outcome. Costeffectiveness dilakukan untuk melakukan pengendalian biaya agar tidak terjadi pemborosan dana di RSUD Dr. Soetomo. Oleh karena itu penulis ingin melakukan penelitian terhadap cost-effectiveness Program Pening-katan Pelayanan Badan Layanan Umum Daerah (BLUD) di RSUD Dr. Soetomo Tahun 2015.

\section{METODE PENELITIAN}

\section{Jenis dan Rancangan Penelitian}

Penelitian ini merupakan penelitian deskriptif dengan pendekatan kuantitatif. Peneliti berusaha untuk menggambarkan bagaimanakah cost-effectiveness pelaksanaan Program Peningkatan Pelayanan Badan Layanan Umum Daerah (BLUD) di RSUD Dr. Soetomo Tahun 2015.

\section{Tempat dan Waktu Penelitian}

Penelitian ini dilaksanakan di Rumah Sakit Dr. Soetomo tepatnya di unit Perencanaan Program. Waktu penelitian ini dilakukan selama 16 Mei - 24 Juni 2016.

\section{Subyek Penelitian}

Subyek penelitian dalam penelitian ini adalah Dokumen Sistem Akuntabilitas Kinerja Instalasi Pemerintah (SAKIP) yaitu Rencana strategis RSUD Dr. Soetomo Tahun 2015, Dokumen Rencana Kinerja Tahunan (RKT) Tahun 2015, Dokumen Perubahan Pelaksanaan Anggaran (DPPA) Tahun 2015, Laporan Akuntabilitas Kinerja Instansi Pemerintah (LAKIP) Tahun 2015.

\section{Instrumen Penelitian}


Instrumen penelitian yang digunakan pada penelitian ini berupa lembar pengumpul data (LPD). LPD digunakan sebagai alat bantu untuk mengumpulkan data dari dokumen SAKIP RSUD Dr. Soetomo Tahun 2015.

\section{Metode Pengumpulan Data}

Metode pengumpulan data yang digunakan penulis dalam penelitian ini adalah dokumentasi. Menurut Sugiyono (2013:240) dokumen merupakan catatan peristiwa yang sudah berlalu. Dokumen bisa berbentuk tulisan, gambar, atau karyakarya monumental dari seorang. Dokumen yang berbentuk tulisan misalnya catatan harian, sejarah kehidupan (life histories), ceritera, biografi, peraturan, kebijakan. Adapun data dokumen Sistem Akuntabilitas Kinerja Instansi Pemerintah (SAKIP) Rumah Sakit Dr. Soetomo Surabaya tahun 2015 yaitu Rencana strategis RSUD Dr. Soetomo Tahun 2015, Dokumen Rencana Kinerja Tahunan (RKT) Tahun 2015, Dokumen Perubahan Pelaksanaan Anggaran (DPPA) Tahun 2015, Laporan Akuntabilitas Kinerja Instansi Pemerintah (LAKIP) Tahun 2015.

\section{Metode Analisis Data}

Analisa data yang digunakan adalah secara deskriptif kualitatif yaitu analisis yang didasarkan pada perhitungan untuk mengetahui tingkat rasio. Rasio yang digunakan adalah cost-effectiveness dengan perhitungan sebagai berikut:

$$
\text { Cost }- \text { effectiveness }=\frac{\text { Cost }}{\text { Outcome }}
$$

\section{HASIL PENELITIAN PEMBAHASAN}

\section{Input}

Input adalah semua jenis sumber daya masukan yang digunakan dalam suatu proses tertentu untuk menghasilkan suatu output. Input tersebut bisa berupa bahan baku untuk proses, orang, infrastruktur seperti gedung dan peralatan, teknologi (hardware dan software). Menurut mahmudi (2015) Input dibagi menjadi 2 yaitu Input primer dan Input sekunder. Input primer adalah kas, sedangkan Input sekunder adalah bahan baku, orang, infrastruktur, dan masukan lainnya yang digunakan untuk proses menghasilkan output.

Pengukuran Input adalah pengukuran sumber daya yang dikonsumsi oleh suatu proses dalam rangka menghasilkan output. Proses tersebut dapat berbentuk program atau aktivitas. Ukuran Input mengindikasikan jumlah sumber daya yang dikonsumsi untuk suatu program, aktivitas, atau organisasi. Pengukuran Input dilakukan dengan cara membandingkan Input sekunder dengan Input primer. Dengan kata lain, pengukuran Input adalah untuk mengetahui harga per unit. Harga Input tersebut diidentifikasi melalui akuntansi biaya, yaitu dengan pembebanan biaya (costing). Biaya Input tersebut dikaitkan dengan output dengan cara membebankan ke anggaran program yang bersang-kutan. Indikator Input yang digunakan indikator finansial berupa anggaran.

Dalam penelitian ini Input yang digunakan adalah cost (biaya). Jumlah SDM (Sumber Daya Manusia) tidak diidentifikasi karena penelitian ini lebih menitikberatkan kepada penggunaan dana. IKU 1 mendapatkan dana dari 3 program yaitu:

1. Program Pelaksanaan Adminis-trasi Perkantoran (non fungsional),

2. Program Sarana Dan Prasarana Aparatur (non fungsional) Dan

3. Program Pelaksanaan Peningkatan Pelayanan Badan Layanan Umum Daerah (BLUD)(fungsional).

Dana yang digunakan untuk mendukung IKU 1 sebesar $87 \%$ dari dana yang dianggarkan. Dana tersebut digunakan sebagai sumberdana untuk tiga Bidang /Bagian. Bidang Pelayanan Medik dengan sembilan kegiatan, Bidang Pelayanan Diagnostik dan Khusus dengan tujuh kegiatan, dan Bidang Keperawatan dengan sembilan kegiatan.

IKU 2 mendapatkan dana dari 3 program yaitu: 
1. Program Pelaksanaan Adminis-trasi Perkantoran (non fungsional),

2. Program Sarana Dan Prasarana Aparatur (non fungsional) Dan

3. Program Pelaksanaan Peningkat-an Pelayanan Badan Layanan Umum Daerah (BLUD) (fungsional)

Dana yang digunakan sebesar $97 \%$ dari dana yang dianggarkan. Dana tersebut digunakan sebagai sumberdana untuk Bidang Pelayanan Diagnostik dan Khusus dengan tujuh kegiatan.

IKU 3 mendapatkan dana dari 3 program yaitu:

1. Program Pelaksanaan Adminis trasi Perkantoran (non fungsional),

2. Program Sarana Dan Prasarana Aparatur (non fungsional) Dan

3. Program Pelaksanaan Peningkat-an Pelayanan Badan Layanan Umum Daerah (BLUD) (fungsional)

Dana yang digunakan sebesar $78 \%$ dari dana yang dianggarkan. Dana tersebut digunakan sebagai sumberdana untuk Bidang Pelayanan Medik dengan sembilan kegiatan.

IKU 4, 5, 6, 7 mendapatkan dana dari 3 program yaitu:

1. Program Pelaksanaan Adminis-trasi Perkantoran (non fungsional),

2. Program Sarana Dan Prasarana Aparatur (non fungsional) Dan

3. Program Pelaksanaan Peningkatan Pelayanan Badan Layanan Umum Daerah (BLUD) (fungsional)

Dana yang digunakan sebesar $87 \%$ dari dana yang dianggarkan. Dana tersebut digunakan sebagai sumberdana untuk dua Bidang /Bagian. Bidang Pelayanan Medik dengan sembilan kegiatan, dan Bidang Keperawatan dengan sembilan kegiatan.

IKU 8 mendapatkan dana dari 3 program yaitu:

1. Program Pelaksanaan Adminis-trasi Perkantoran (non fungsional),

2. Program Sarana Dan Prasarana Aparatur (non fungsional) Dan

3. Program Pelaksanaan Pening-katan Pelayanan Badan Layanan Umum Daerah (BLUD)(fungsional)
Dana yang digunakan sebesar $78 \%$ dari dana yang dianggarkan. Dana tersebut digunakan sebagai sumberdana untuk Bidang Pelayanan Medik dengan sembilan kegiatan.

IKU 9 mendapatkan dana dari 3 program yaitu:

1. Program Pelaksanaan Adminis-trasi Perkantoran (non fungsional),

2. Program Sarana Dan Prasarana Aparatur (non fungsional) Dan

3. Program Pelaksanaan Pening-katan Pelayanan Badan Layanan Umum Daerah (BLUD) (fungsional)

Dana yang digunakan sebesar 90\% dari dana yang dianggarkan. Dana tersebut digunakan sebagai sumberdana untuk empat Bidang /Bagian yaitu Bidang Pelayanan Medik dengan sembilan kegiatan, Bidang Pelayanan Diagnostik dan Khusus dengan 7 kegiatan, Bidang Perbekalan dan Peralatan Medik dengan tujuh kegiatan, Bidang Pemasaran Dan Rekam Medik dengan lima belas kegiatan. IKU 10 mendapatkan dana dari 3 program yaitu:

1. Program Pelaksanaan Admi-nistrasi Perkantoran (non fungsional),

2. Program Sarana Dan Prasarana Aparatur (non fungsional) Dan

3. Program Pelaksanaan Pening-katan Pelayanan Badan Layanan Umum Daerah (BLUD) (fungsional)

Dana yang digunakan sebesar $87 \%$ dari dana yang dianggarkan. Dana tersebut digunakan sebagai sumberdana untuk lima Bidang /Bagian yaitu Bidang Pelayanan Medik dengan sembilan kegiatan, Bidang Perbekalan dan Peralatan Medik dengan tujuh kegiatan, Bagian Perencanaan Program dengan tigabelas kegiatan, Bidang Tata Usaha dengan enam kegiatan, Bagian Kepegawaian dengan sebelas kegiatan.

IKU 11 dan 12 mendapatkan dana dari 2 program yaitu:

1. Program Peningkatan Kapasitas Kelembagaan Pemerintah Daerah (non fungsional) 
2. Program Pelaksanaan Pening-katan Pelayanan Badan Layanan Umum Daerah (BLUD) (fungsional)

Dana yang digunakan sebesar $97 \%$ dari dana yang dianggarkan. Dana tersebut digunakan sebagai sumberdana untuk Bidang Pendidikan dan Pelatihan dengan enam kegiatan.

IKU 13 mendapatkan dana dari 2 program yaitu:

1. Program Peningkatan Kapasitas Kelembagaan Pemerintah Daerah (non fungsional)

2. Program Pelaksanaan Pening-katan Pelayanan Badan Layanan Umum Daerah (BLUD) (fungsional)

Dana yang digunakan sebesar $73 \%$ dari dana yang dianggarkan. Dana tersebut digunakan sebagai sumberdana untuk Bidang Penelitian dan Pengembangan dengan tigabelas kegiatan.

IKU 14 mendapatkan dana dari 3 program yaitu:

1. Program Pelaksanaan Adminis trasi Perkantoran (non fungsional)

2. Program Peningkatan Sarana dan Prasarana (non fungsional)

3. Program Pelaksanaan Pening-katan Pelayanan Badan Layanan Umum Daerah (BLUD) (fungsional)

Dana yang digunakan sebesar $75 \%$ dari dana yang dianggarkan. Dana tersebut digunakan sebagai sumberdana untuk Bagian Keuangan dengan sepuluh kegiatan dan Bagian Perencnaan Program dengan tigabelas kegiatan.

\section{Output}

Output adalah hasil langsung dari suatu proses. Contoh output adalah jumlah operasi yang dilakukan oleh dokter bedah, jumlah lulusan perguruan tinggi, jumlah pasien yang datang ke rumah sakit.

Pengukuran output adalah pengukuran keluaran langsung suatu proses. Ukuran output menunjukkan hasil implementasi program atau aktivitas. Pengukuran output berbentuk kuantitatif dan keuangan atau kuantitatif nonkeuangan. Sebagai contoh output yang bersifat kuantitatif keuangan adalah jumlah pendapatan yang diperoleh oleh departemen pemasaran atau Badan Pengelola Keuangan Daerah. Output juga bersifat kuantitatif nonkeuangan yang dinyatakan dalam bentuk unit fisik misalnya adalah jumlah operasi jantung yang dilakukan, jumlah lulusan perguruan tinggi, panjang jalan yang diaspal, jumlah tong sampah yang dikumpulkan, jumlah sekolah yang dibangun, jumlah undangundang yang dihasilkan, jumlah peserta penyuluhan dan sebagainya.

Hasil output pada penelitian ini adalah jumlah sub kegiatan yang dilakukan untuk mendukung kegiatan yang dilakukan oleh setiap Bidang/Bagian. Output dapat juga berupa jumlah dokumen yang dihasilkan dari kegiatan tersebut. Pada IKU 1 dari 25 kegiatan hampir semua kegiatan hasil outputnya adalah 100\%. Output terkecil dari IKU ini adalah $83 \%$ yaitu pada kegiatan penyusunan SPM. Pada IKU 2 terdapat 7 kegiatan dari Bidang Pelayanan Medik dan hasil output hampir semua $100 \%$ tetapi ada 4 kegiatan yang hasil output tidak mencapai $100 \%$ yaitu terdapat pada kegiatan peningkatan kinerja Bidang Pelayanan Diagnostik dan Khusus, peningkatan mutu radiologi terintegrasi, peningkatan kinerja instalasi pelayanan khusus dan peningkatan kinerja SMF Pelayanan Diagnostik dan Khusus. Bidang yang mendukung pelaksanaan IKU 3 adalah Bidang Pelayanan Medik yang mana hasil outputnya tidak berbeda dengan IKU 2. Pada IKU 4,5,6,7, bidang yang mendukung pelaksanaan IKU tersebut adalah Bidang Pelayanan Medik, dan Bidang Keperawatan yang hampir semua hasil dari outputnya adalah $100 \%$. Bidang yang mendukung IKU 8 adalah Bidang Pelayanan Medik, hasil output pada kegiatan ini paling kecil sebesar $83 \%$ pada penyusunan SPM. Pada IKU 9 yang didukung oleh Bidang Pelayanan Medik, Bidang Pelayanan Diagnostik dan khusus, Bidang Perbekalan dan Peralatan Medik, dan Bidang Pemasaran dan Rekam Medik nilai minimal output adalah $33 \%$ untuk kegiatan optimalisasi tim rekam medik. 
Pada IKU 10 didukung Bidang Pelayanan Medik, Bidang Perbekalan dan Peralatan Medik, Bagian Perencanaan Program, Bagian Tata Usaha dan Bagian Kepegawaian yang hasil nilai minimal output adalah $55 \%$ dari kegiatan pemeliharaan kendaraan RS. IKU 11 dan 12 didukung oleh Bidang Pendidikan dan Pelatihan dengan hasil minimal output $38 \%$ pada kegiatan Pelatihan untuk peningkatan ketrampilan dan profesionalisme dokter pendidik dan instruktur klinik internal di luar RSUD Dr. Soetomo (di Pusdiklat/ Badan Diklat, Kongres/ Temu Ilmiah/ Workshop/ Simposium/ Seminar). Hal ini juga terjadi pada IKU 13 yang didukung oleh Bidang Penelitian dan Pengembangan hasilnya semua $100 \%$. Untuk IKU 14 yang didukung oleh Bagian Keuangan dan Bagian Perencanaan Program hasil nilai minimal output adalah 0\% untuk kegiatan penyusunan laporan keuangan BLUD dikarenakan target dokumen yang ditetapkan untuk kegiatan ini adalah 2 dokumen sedangkan yang terealisasi tidak ada.

\section{Outcome}

Outcome yang akan dicapai pada tahun 2015 adalah 14 Indikator Kinerja Utama (IKU) direktur. Outcome ini dicapai dalam waktu satu tahun dan pengukurannya dalam jangka waktu yang lama. Dibawah ini adalah uraian sasaran, IKU dan capaian dari IKU pada tahun 2015.

Tabel 1 Capaian Indikator Kinerja Utama RSUD Dr. Soetomo Tahun 2015

\begin{tabular}{|c|c|c|}
\hline Sasaran & Indikator Sasaran & $\begin{array}{l}\text { Nilai Kinerja } \\
\text { Outcome }\end{array}$ \\
\hline \multirow[t]{10}{*}{$\begin{array}{l}\text { Meningkatnya mutu } \\
\text { pelayanan rumah sakit }\end{array}$} & 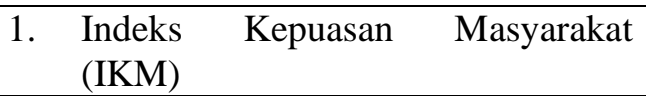 & $102,5 \%$ \\
\hline & $\begin{array}{l}\text { 2. Prosentase Pemenuhan kebutuhan } \\
\text { Jaringan }\end{array}$ & $100 \%$ \\
\hline & $\begin{array}{l}\text { 3. Prosentase Pasien di Gawat Darurat } \\
\text { yang dilayani }<5 \text { menit }\end{array}$ & $100 \%$ \\
\hline & 4. $\quad$ Bed Occupancy Rate (BOR) & $93,04 \%$ \\
\hline & 5. Average Length of Stay (ALOS) & $89,14 \%$ \\
\hline & 6. $\quad$ Bed Turn Over (BTO) & $84,35 \%$ \\
\hline & 7. Turn Over Interval (TOI) & $89,2 \%$ \\
\hline & 8. Net Death Rate (NDR) & $48 \%$ \\
\hline & $\begin{array}{l}\text { 9. Prosentase Capaian Indikator SPM } \\
\text { yang memenuhi target }\end{array}$ & $100 \%$ \\
\hline & $\begin{array}{l}\text { 10. Prosentase Elemen JCI yang } \\
\text { memenuhi standar }\end{array}$ & $100,57 \%$ \\
\hline \multirow{2}{*}{$\begin{array}{l}\text { Meningkatnya mutu } \\
\text { pendidikan/pelatihan } \\
\text { di rumah sakit }\end{array}$} & $\begin{array}{l}\text { 11. Prosentase Peserta Didik PPDS I } \\
\text { yang dilatih dan lulus }\end{array}$ & $100 \%$ \\
\hline & $\begin{array}{l}\text { 12. Prosentase pemenuhan pelatihan } \\
\text { yang diadakan untuk } \\
\text { kesehatan di luaraga } \\
\text { Dr.Soetomo }\end{array}$ & $189,86 \%$ \\
\hline $\begin{array}{l}\text { Meningkatnya mutu } \\
\text { penelitian kesehatan } \\
\text { yang dilakukan di } \\
\text { rumah sakit }\end{array}$ & $\begin{array}{l}\text { 13. Prosentase penelitian uji klinik } \\
\text { yang lulus kelayakan etik (ethical } \\
\text { clearance) }\end{array}$ & $100 \%$ \\
\hline
\end{tabular}




\begin{tabular}{|c|c|c|c|}
\hline \multicolumn{1}{|c|}{ Sasaran } & \multicolumn{1}{|c|}{ Indikator Sasaran } & $\begin{array}{c}\text { Nilai Kinerja } \\
\text { Outcome }\end{array}$ \\
\hline $\begin{array}{l}\text { Meningkatnya tingkat } \\
\text { kemandirian keuangan } \\
\text { di rumah sakit }\end{array}$ & 14. Cost Recovery Ratio (CRR) & $102,58 \%$ \\
\hline
\end{tabular}

Sumber: Dokumen Laporan Evaluasi Kinerja Direktur Tahun 2015

\section{Cost-Effectiveness}

Cost Effectiveness Analysis digunakan apabila benefit sulit ditransformasikan dalam bentuk uang sehingga CEA sangat baik untuk mengukur efisiensi di bidang sosial, khususnya bidang kesehatan yang bersifat program/intervensi pada tingkat kabupaten/kota. Penelitian ini menggunakan analisa cost-effectiveness pada dasarnya untuk mengetahui seberapa efektif dana yang dihabiskan untuk memperoleh suatu manfaat. Pada dasarnya semakin kecil Input yang dikeluarkan tetapi outcome yang dihasilkan lebih besar maka hasil dari kategori cost-effectiveness semakin besar. Ada sedikit perbeda-an pengukuran efektifitas dengan pengukuran cost-effectiveness, pada pengukuran efektivitas diperoleh dari perbandingan antara outcome dengan output sedangkan pada pengukuran cost-effectiveness konsep efektivitas diperoleh dari perbandingan antara outcome dengan Input (biaya). Dibawah ini hasil perhitungan cost effectiveness terhadap IKU Direktur.

Cost - effectiveness $=\frac{\text { Cost }}{\text { Outcome }}$ Tabel 2 .

Hasil Pengukuran Cost-Effectiveness Pada 14 IKU

Di RSUD Dr Soetomo Tahun 2015

\begin{tabular}{|l|l|l|l|}
\hline No & \multicolumn{1}{|c|}{ IKU } & Rata-rata & $\begin{array}{c}\text { Cost } \\
\text { Effectiveness }\end{array}$ \\
\hline 1 & $\begin{array}{l}\text { Indeks } \\
\text { Kepuasan } \\
\text { Masyarakat } \\
\text { (IKM) }\end{array}$ & $90,8 \%$ & Cukup Efektif \\
\hline 2 & $\begin{array}{l}\text { Prosentase } \\
\text { Pemenuhan } \\
\text { kebutuhan } \\
\text { Jaringan }\end{array}$ & $97 \%$ & Cukup Efektif \\
\hline 3 & $\begin{array}{l}\text { Prosentase } \\
\text { Pasien di di } \\
\text { Gawat } \\
\text { Darurat yang } \\
\text { dilayani } \\
\text { menit 5 }\end{array}$ & $87 \%$ & Cukup Efektif \\
\hline
\end{tabular}

\begin{tabular}{|c|c|c|c|}
\hline No & IKU & Rata-rata & $\begin{array}{c}\text { Cost } \\
\text { Effectiveness }\end{array}$ \\
\hline 4 & $\begin{array}{l}\text { Bed } \\
\text { Occupancy } \\
\text { Rate (BOR) }\end{array}$ & $98,2 \%$ & Cukup Efektif \\
\hline 5 & $\begin{array}{l}\text { Average } \\
\text { Length of } \\
\text { Stay }(A L O S)\end{array}$ & $102,5 \%$ & Cukup Efektif \\
\hline 6 & $\begin{array}{l}\text { Bed Turn } \\
\text { Over (BTO) }\end{array}$ & $108,3 \%$ & Kurang Efektif \\
\hline 7 & $\begin{array}{l}\text { Turn Over } \\
\text { Interval } \\
\text { (TOI) }\end{array}$ & $102,5 \%$ & Cukup Efektif \\
\hline 8 & $\begin{array}{l}\text { Net Death } \\
\text { Rate }(\text { NDR })\end{array}$ & $181 \%$ & Tidak Efektif \\
\hline 9 & $\begin{array}{l}\text { Prosentase } \\
\text { Capaian } \\
\text { Indikator } \\
\text { SPM yang } \\
\text { memenuhi } \\
\text { target }\end{array}$ & $91 \%$ & Cukup Efektif \\
\hline 10 & $\begin{array}{l}\text { Prosentase } \\
\text { Elemen JCI } \\
\text { yang } \\
\text { memenuhi } \\
\text { standar }\end{array}$ & $83,7 \%$ & Cukup Efektif \\
\hline 11 & $\begin{array}{l}\text { Prosentase } \\
\text { Peserta Didik } \\
\text { PPDS I yang } \\
\text { dilatih dan } \\
\text { lulus }\end{array}$ & $95 \%$ & Cukup Efektif \\
\hline 12 & $\begin{array}{l}\text { Prosentase } \\
\text { pemenuhan } \\
\text { pelatihan } \\
\text { yang } \\
\text { diadakan } \\
\text { untuk tenaga } \\
\text { kesehatan di } \\
\text { luar RSUD } \\
\text { Dr.Soetomo }\end{array}$ & $50,0 \%$ & Efektif \\
\hline 13 & $\begin{array}{l}\text { Prosentase } \\
\text { penelitian uji } \\
\text { klinik yang } \\
\text { lulus } \\
\text { kelayakan } \\
\text { etik (ethical } \\
\text { clearance) }\end{array}$ & $84 \%$ & Cukup Efektif \\
\hline 14 & $\begin{array}{l}\text { Cost } \\
\text { Recovery } \\
\text { Ratio (CRR) }\end{array}$ & $76,9 \%$ & Cukup Efektif \\
\hline \multicolumn{2}{|c|}{ Rata-rata } & $96,3 \%$ & Cukup \\
\hline
\end{tabular}




\begin{tabular}{|l|c|c|c|}
\hline No & IKU & Rata-rata & $\begin{array}{c}\text { Cost } \\
\text { Effectiveness }\end{array}$ \\
\hline \multicolumn{2}{|l}{} & Efektif \\
\hline
\end{tabular}

Berdasarkan tabel diatas ada 1 IKU yaitu Prosentase pemenuhan pelatihan yang diadakan untuk tenaga kesehatan di luar RSUD Dr.Soetomo termasuk dalam kategori Efektif. Ada 11 IKU yaitu Indeks Kepuasan Masyarakat (IKM), Prosentase Pemenuhan kebutuhan Jaringan, Prosentase Pasien di Gawat Darurat yang dilayani < 5 menit, Bed Occupancy Rate (BOR), Average Length of Stay (ALOS), Turn Over Interval (TOI), Prosentase Capaian Indikator SPM yang memenuhi target, Prosentase Elemen JCI yang memenuhi standar, Prosentase Peserta Didik PPDS I yang dilatih dan lulus, Prosentase penelitian uji klinik yang lulus kelayakan etik (ethical clearance) dan Cost Recovery Ratio (CRR) termasuk dalam kategori cukup efektif. IKU Bed Turn Over (BTO) termasuk dalam kategori kurang efektif. Sedangkan IKU Net Death Rate (NDR) termasuk kedalam kategori tidak efektif dapat dilakukan evaluasi seperti pada teori Mulyadi (2007) yaitu:

1. Mengurangi aktivitas bukan penambah nilai (activity reduction)

2. Menghilangkan aktivitas bukan penambah nilai (activity elimination)

3. Membagi aktivitas penambah nilai (activity sharing)

4. Memilih aktivitas penambah nilai (activity selection)

\section{Kesimpulan}

Berdasarkan pada data yang telah diolah dari hasil analisis data maka dapat ditarik kesimpulan sebagai berikut :

1. Berdasarkan pada identifikasi Input Indikator Kinerja Utama dalam Di RSUD Dr. Soetomo Tahun 2015

Nilai kinerja Input yang paling besar adalah $97 \%$ pada IKU 1 yaitu Indeks Kepuasan Masyarakat (IKM) dan IKU 2 Prosentase Pemenuhan kebutuhan Jaringan. Sedangkan nilai kinerja Input yang paling kecil yaitu $73 \%$ pada IKU
13 yaitu Prosentase penelitian uji klinik yang lulus kelayakan etik (ethical clearance).

2. Berdasarkan pada identifikasi Output Indikator Kinerja Utama dalam Di RSUD Dr. Soetomo Tahun 2015.

Hasil output pada penelitian ini adalah jumlah sub kegiatan yang dilakukan untuk mendukung kegiatan yang dilakukan oleh setiap Bidang/Bagian. Output dapat juga berupa jumlah dokumen yang dihasilkan dari kegiatan tersebut.

3. Berdasarkan hasil identifikasi Outcome Indikator Kinerja Utama dalam Di RSUD Dr. Soetomo Tahun 2015.

Outcome yang akan dicapai pada tahun 2015 adalah 14 Indikator Kinerja Utama (IKU) direktur. Outcome ini dicapai dalam waktu satu tahun dan pengukurannya dalam jangka waktu yang lama. Dibawah ini adalah rincian IKU Direktur:

a. Indeks Kepuasan Masyarakat

b. Prosentase Pemenuhan kebutuhan Jaringan

c. Prosentase Pasien di Gawat Darurat yang dilayani $<5$ menit

d. Bed Occupancy Rate (BOR)

e. Average Length of Stay (ALOS)

f. Bed Turn Over (BTO)

g. Turn Over Interval (TOI)

h. Net Death Rate (NDR)

i. Prosentase Capaian Indikator SPM yang memenuhi target

j. Prosentase Elemen JCI yang memenuhi standar

k. Prosentase Peserta Didik PPDS I yang dilatih dan lulus

1. Prosentase pemenuhan pelatihan yang diadakan untuk tenaga kesehatan di luar RSUD Dr.Soetomo

m. Prosentase penelitian uji klinik yang lulus kelayakan etik (ethical clearance)

n. Cost Recovery Ratio (CRR)

4. Analisis cost-effectiveness Pelaksanaan Program Pening-katan Pelayanan 
Badan Layanan Umum Daerah (BLUD)

Di RSUD Dr. Soetomo Tahun 2015.

Hasil dari analisis Program Peningkatan Pelayanan Badan Layanan Umum Daerah (BLUD) Di RSUD Dr. Soetomo Tahun 2015 berjalan secara efektif. Hal ini didukung dengan hasil perhitungan costeffectiveness pada 14 IKU Direktur menunjukkan $96,3 \%$ dan termasuk dalam kategori cukup efektif.

\section{Saran}

Berdasarkan pada hasil dan pembahasan penelitian yang dilakukan pada cost effectiveness Program Pelaksanaan Peningkatan Pelayanan Badan Layanan Umum Daerah (BLUD) terdapat beberapa saran yang dapat diberikan yakni :

1. Dalam penelitian ini terdapat kelemahan yakni adanya variasi data yang terdapat di Rumah Sakit sehingga data yang ada harus divalidasi terlebih dahulu.

2. Pada pengukuran cost effectiveness terdapat hasil Indikator kinerja Utama yang termasuk kedalam kategori "tidak efektif", "kurang efektif" dan "cukup efektif, dan efektif diharapkan pihak Rumah Sakit dapat melakukan evaluasi terhadap kegiatan dan dana yang dianggarkan. Pihak manajemen dapat melakukan pengurangan sub kegiatan bukan penambah nilai, menghilangkan sub kegiatan penambah nilai, membagi sub kegiatn penambah nilai dan menambah sub kegiatan penambah nilai.

\section{DAFTAR PUSTAKA}

Keputusan Menteri Dalam Negeri No. 29 Tahun 2009 Pedoman Pengurusan, Pertanggungjawaban Dan Pengawasan Keuangan Daerah Serta Tata Cara Penyusunan Anggaran Pendapatan Dan Belanja Daerah, Pelaksanaan Tata Usaha Keuangan Daerah Dan Penyusunan Perhitungan Anggaran Pendapatan Dan Belanja
Daerah Kepala Pusat Kajian Hukum 10 Juni 2000. Jakarta.

Mahmudi, 2015. Manajemen Kinerja Sektor Publik. Edisi Ketiga. Yogyakarta : UPP STIM YKPN.

Mark S.Thompson. 1980. First Principles of Cost-Effectiveness Analysis in Health. English Publication in Public Health Reports 93:535 - 543.

Moeheriono, 2012. Indikator Kinerja Utama. Jakarta: Rajawali Pers.

Mulyadi, 2007. Activity Based Cost System. Yogyakarta : UPP STIM YKPN.

Peraturan Menteri Pendayagunaan Aparatur Negara Dan Reformasi Birokrasi Republik Indonesia No 53 Tahun 2014 Petunjuk Teknis Perjanjian Kinerja, Pelaporan Kinerja Dan Tata Cara Reviu Atas Laporan Kinerja.Instansi Pemerintah 20 November 2014.Berita Negara Republik Indonesia Tahun 2014 Nomor 1842.Jakarta.

Peraturan Pemerintah Republik Indonesia No. 23 Tahun 2005 Pengelolaan Keuangan Badan Layanan Umum. Menteri Hukum dan Hak Asasi Manusia Republik Indonesia 13 Juni 2015. Lembaran Negara Republik Indonesia Tahun 2005 Nomor 48. Jakarta.

Sabarguna B, 2007. Manajemen Keuangan Rumah Sakit. Yogyakarta; Konsorsium Rumah Sakit Jateng-DIY.

Sugiyono.2013. Metode Penelitian kuantitatif, kualitatif dan $R \& D$. http://rayendar.blogspot.co.id/2015/06 /metode-penelitian-menurut-sugiyono2013.html . (24 April 2016)

Sugiyono.2007. Statistika Untuk Penelitian. Bandung:CV Alfabeta.

Tjiptoherijanto. 1994. Ekonomi Kesehatan. Jakarta: PT. Rineka Cipta.

Undang-Undang No 44 Tahun 2009 Rumah Sakit. Presiden Republik Indonesia 28 Oktober 2009. Menteri Hukum dan Hak Asasi Manusia Republik Indonesia 28 Oktober 2009. 
Lembaran Negara Republik Indonesia Tahun 2009 Nomor 153. Jakarta.

Undang-Undang No 17 Tahun 2003 Keuangan Negara. Sekretaris Negara Republik Indonesia 5 April 2003. Lembaran Negara Republik Indonesia Tahun 2003 Nomor 47. Jakarta.

Wijono, Djoko. 2007. Evaluasi Program Kesehatan dan Rumah Sakit. Surabaya. CV. Duta Prima Airlangga. 